A Comparison of Mechanical Properties and Scaling Law Relationships for Silica Aerogels and Their Organic Counterparts

\author{
R. W. Pekala \\ L. W. Hrubesh \\ T. M. Tillotson \\ C. T. Alviso \\ J. F. Poco \\ J. D. LeMay
}

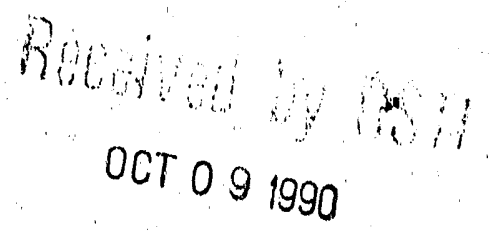

This paper was prepared for submittal to Materials Research Society

Symposium W: Scailing in Disordered Materials Boston, MA

November 26 - December 1, 1990

August 1990

This is a preprint of a paper intended for publication in a journal or proceedings. Since changes may be made before publication, this preprint is made available with the understanding that it will not be cited or reproduced without the permission of the author.
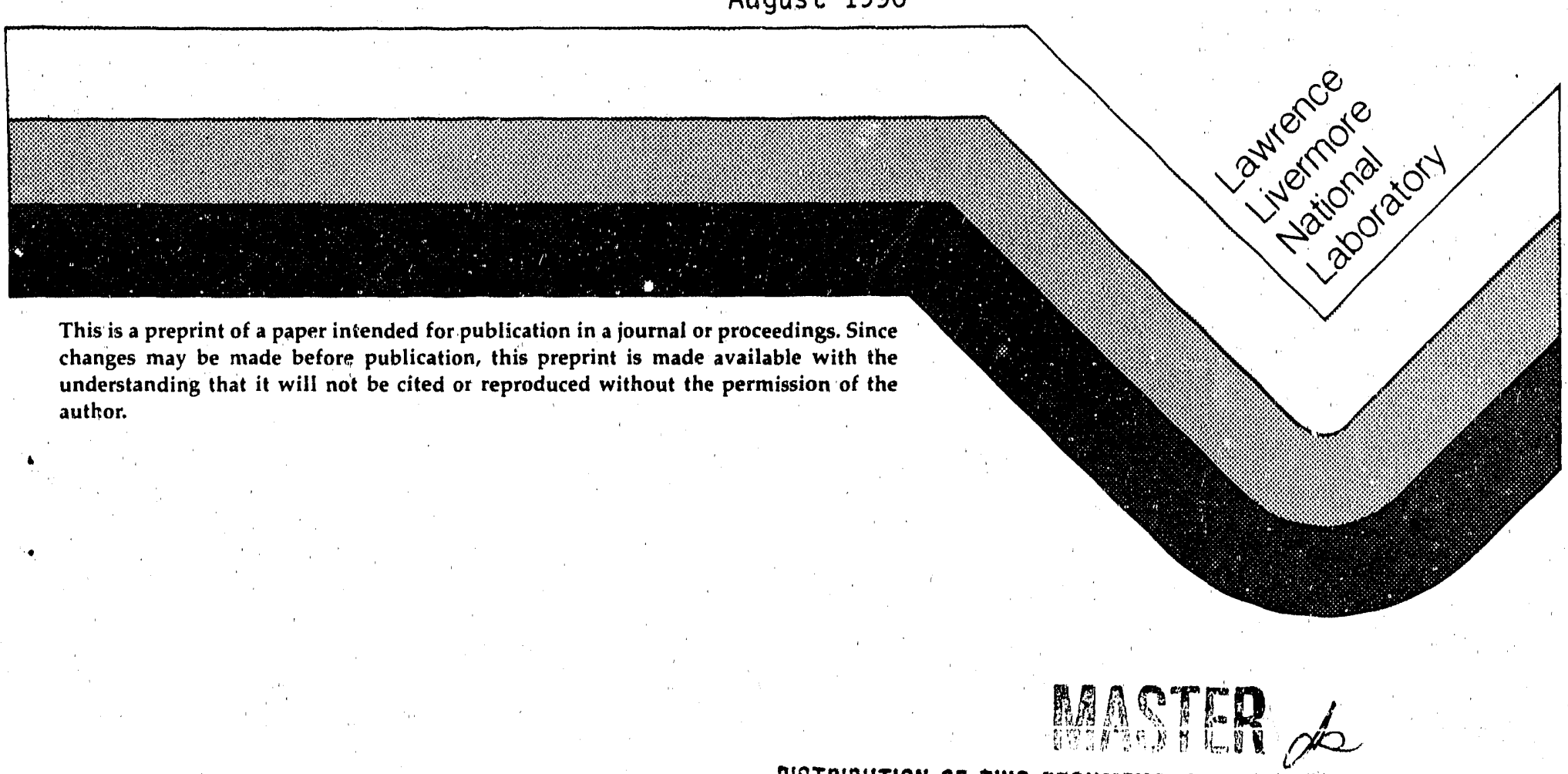


\title{
A COMPARISON OF MECHANICAL PROPERTIES AND SCALING LAW RELATIONSHIPS FOR SILICA AEROGELS AND THEIR ORGANIC COUNTERPARTS
}

\author{
R.W. Pekala, L.W. Hrubesh, T.M. Tillotson, C.T. Alviso, J.F. Poco, and J.D. LeMay, \\ Chemistry \& Materials Science Department, Lawrence Livermore National Laboratory, Livermore, \\ CA 94550.
}

\section{INTRODUCTION}

Aerogels are a special class of open-cell foams derived from the supercritical extraction of highly crosslinked, inorganic or organic gels, The resultant materials have ultrafine cell/pore sizes $(<100 \mathrm{~nm})$, high surface areas $\left(350-1000 \mathrm{~m}^{2} / \mathrm{g}\right)$, and a microstructure composed of interconnected colloidal-like particles or polymeric chains with characteristic diameters of $10 \mathrm{~nm}$. TEM and SAXS show that this microstructure is sensitive to variations in processing conditions that influence crosslinking chemistry and growth processes prior to gelation [1-4].

Traditional silica aerogels are prepared via the hydrolysis and condensation of tetramethoxy silane (TMOS) or tetraethoxy silane (TEOS). Factors such as $\mathrm{pH}$ and the $\left[\mathrm{H}_{2} \mathrm{O}\right] /[\mathrm{TMOS}]$ ratio affect the microstructure of the dried aerogel. It is generally accepted that 'polymeric' silica aerogels result from acid catalysis while 'colloidal' silica aerogels result from base catlaysis [5]. Recently, Hrubesh and Tillotson developed a new 'condensed silica' procedure for obtaining silica aerogels with densities as low as $0.004 \mathrm{~g} / \mathrm{cc}$, i.e. only $3 \mathrm{X}$ the density of air [6-8]!

Organic aerogels are formed from the aqueous, pol jcondensation of (1) resorcinol/formaldehyde or (2) melamine/formaldehyue. The microstructure of the resorcinolformaldehyde (RF) aerogels is dictated by the amount of base catalyst used in the sol-gei polymerization. In addition, these materials can be pyrolyzed in an inert atmosphere to form vitreous carbon aerogels [9-11]. Melamine-formaldehyde (MF) aerogels that are both colorless and transparent are only formed under acidic conditions (i.e. $\mathrm{pH}=1-2$ ) [12].

In this paper, the microstructural dependence and scaling law relationships for the compressive modulus of silica, carbon, RF, and MF aerogels will be discussed in detail.

\section{EXPERIMENTAL}

\section{Synthesis}

Aerogel preparation has been described elsewhere [10]. Briefly, all RF aerogels were synthesized from aqueous solutions containing various \% solids at a constant [formaldehyde]/[resorcinol] ratio equals 2.0 . Sodium carbonate was used as a base catalyst, and all formulations were referenced by their [Resorcinol]/[Catalyst] ratio. $\mathrm{R} / \mathrm{C}$ ratios of 50-300 produced transparent gels. After curing the gels for up to 7 days at $95^{\circ} \mathrm{C}$, they were further crosslinked in a dilute acid solution, and then exchanged into an organic solvent (e.g. isopropanol). All RF gels were supercritically dried from carbon dioxide $\left(T_{c}=31^{\circ} \mathrm{C} ; \mathrm{P}_{c}=7.6 \mathrm{MPa}\right)$. The red-colored RF aerogels were pyrolyzed in an inert atmosphere at $1050^{\circ} \mathrm{C}$ to produce vitreous carbon aerogels.

Melamine-formaldehyde aerogels were also synthesized from aqueous solutions containing various \%solids with a constant [formaldehyde]/[melamine] ratio equals 3.7. Initially, the MF slurry was heated at $70^{\circ} \mathrm{C}$ under basic conditions to give a clear polymer solution. The polymer solution was then cooled to $45^{\circ} \mathrm{C}$ and acidified with $\mathrm{HCl}$. This mixture was cast into glass vials and cured for up to 14 days at $95^{\circ} \mathrm{C}$. The resultant gels were neutralized and then exchanged into an organic solvent (e.g. acetone). All MF gels were supercritically dried from carbon dioxide to give aerogels that were both colorless and transparent. 
Silica aerogels were synthesized from tetramethoxy silane (TMOS). In the case of the acid $\left(\mathrm{HBF}_{4}\right)$ and base $\left(\mathrm{NH}_{4} \mathrm{OH}\right)$ catalyzed gels, methanol was used as the diluent and a $\left[\mathrm{H}_{2}, \mathrm{O}\right] /[\mathrm{Si}]$ ratio of 4.0 was utilized. In the 'condensed silica' procedure, TMOS was refluxed under acidic $(\mathrm{HCl})$ conditions with a substoichiometric amount of water. The resultant methanol was distilled off to give a viscous oil. This 'condensed silica' was dissolved in acetone, additional water was added to bring the overall $\left[\mathrm{H}_{2} \mathrm{O}\right] /[\mathrm{Si}]$ ratio to 4.0 , and the mixture was catalyzed under basic $\left(\mathrm{NH}_{4} \mathrm{OH}\right)$ conditions to produce crosslinked gels [8]. All silica gels were dried in an autoclave above the critical point of their respective diluents (methanol $\mathrm{T}_{\mathrm{c}}=240^{\circ} \mathrm{C} \mathrm{P}_{\mathrm{c}}=8.0 \mathrm{MPa}$; acetone $\mathrm{T}_{\mathrm{c}}=236^{\circ} \mathrm{C} \mathrm{P}_{\mathrm{c}}=4.8 \mathrm{MPa}$ ).

\section{Mechanical Testing}

The modulus and strength of aerogels were measured in uniaxial compression with an Instron machine (model \#1125). The tests were performed at an initial strain rate of $0.1 \% / \mathrm{sec}$. All measurements were made under ambient conditions at $\sim 22^{\circ} \mathrm{C}$ and $50-70 \%$ relative humidity. No precautions were taken to prevent moisture adsorption by the aerogels.

Test specimens were either machined into $1 \times 1 \times 1 \mathrm{~cm}^{3}$ cubes or were $1-2 \mathrm{~cm}$ long cylinders cut from molded samples. Great care was exercised to ensure that specimens were machined with flat, smooth faces and plane-parallel opposing faces. The surfaces of as-produced aerogels were completely removed to eliminate possible contributions from surface skins. The density of each specimen was determined just prior to testing, and the compressive modulus was derived from the linear region of the stress-srain curve.

\section{RESULTS AND DISCUSSION}

As a result of their high porosity, aerogels exhibit elastic moduli many orders of magnitude smaller than their full density analogs. Figure 1 shows the compressive modulus of RF, carbon, $\mathrm{MF}$, and silica aerogels as a function of density and catalyst conditions. As expected, the modulus increases as a function of bulk density. The linear log-log plot in each case demonstrates a powerlaw density dependence that has been observed in many other low density materials. This relationship is expressed as

$$
E=c \rho^{n}
$$

where $\rho$ is the bulk density, $\mathrm{c}$ is a prefactor (constant), and $\mathrm{n}$ is the scaling exponent. For most open-cell foams, the scaling exponent usually falls very close to 2.0 while ideal closed-cell foams give an exponent of 3.0. Foams with irregular, fractal type morphologies generally have values that exceed 3.0 [13-15].

In the case of RF aerogels, the above exponent equals $2.7 \pm 0.2$ for all formulations $[16,17]$. Although the scaling exponents are the same, the prefactors scale inversely with the $\mathrm{R} / \mathrm{C}$ ratio. Previous TEM studies have shown that the interconnected particle size of these aerogels depends upon the $\mathrm{R} / \mathrm{C}$ ratio. At $\mathrm{R} / \mathrm{C}=50$, the particles have diameters of approximately $30 \AA$ and are joined together with large necks between particles. In fact, it is often difficult to visualize individual particles since these networks have a fibrous appearance. At $R / C=300$, the particles have diameters of 160-200 $\AA$ and are lightly fused together giving a "string of pearls" appearance. These RF aerogels have been described as being 'polymeric' and 'colloidal', respectively. Mechanical property data support these descriptions since the modulus increases due to an apparent improvement in particle interconnectivity as the $R / C$ ratio and the particle size decrease.

The scaling exponents $(2.7 \pm 0.2)$ for the carbon aerogels are identical to their RF precursors. In addition, the same rank order is observed for the various formulations, i.e. carbon aerogels prepared at $R / C=50$ have higher moduli than those prepared at $R / C=300$. In general, carbon 
aerogels are $\sim 10 \mathrm{X}$ stiffer than their $\mathrm{RF}$ analogs at equivalent densities and $\mathrm{R} / \mathrm{C}$ ratios.

In the case of silica aerogels, the scaling exponents and prefactors both depend upon catalyst conditions [17]. For acid catalyzed and base catalyzed silica aerogels, the scaling exponents are $3.4 \pm 0.1$ and $2.9 \pm 0.2$, respestively. Over comparable density ranges, the 'polymeric' acid catalyzed silica aerogels are $\sim 7 \mathrm{X}$. stiffer than their 'colloidal' base catalyzed counterparts. The aerogels produced from the 'condensed silica' procedure have a scaling exponent of 3.8 \pm 0.2 . These materials have moduli that are between those of acid and base catalyzed silica aerogels. This result is not surprising since both acid and base catalysis are used in the 2-step, 'condensed silica' procedure.

Interestingly, MF aerogels have a scaling exponent of 3.3 \pm 0.1 and moduli that approximate those of acid catalyzed silica aerogels. In RF and carbon aerogels, a scaling exponent of $2.7 \pm 0.2$ is observed that matches base catalyzed silica aerogels. Considering that in each comparable system, the crosslinking reactions and growth processes take place under similar conditions, similar microstructures might be exprected. Mechanical property, TEM, and surface area data provide some evidence for this hypothesis. Thus, we are continuing to explore commonalities between incrganic and organic aerogels so that a universal model might be developed for the structure and properties of these unique materials.

\section{CONCLUSIONS}

Differences in the mictostructure of organic and silica aerogels are reflected in their compressive properties. In all cases, aerogels exhibit a power-law relationship between modulus and bulk density, but this relationship depends upon matrix material and synthetic conditions. In general, 'polymeric' aerogels are stiffer than 'colloidal' aerogels, independent of the matrix material.

\section{ACKNOWLEDGMENT}

This work was performed under the auspices of the U.S. Department of Energy by Lawrence Livermore National Laboratory under contract \#W-7405-ENG-48

\section{REFERENCES}

[1] C.J. Brinker and G.W. Scherer, Sol-Gel Science (Academic Press, New York, 1990).

[2] Aerogels, ed. by J. Fricke (Springer-Verlag, New York, 1986).

[3] D.W. Schaefer, Science 243, 1023 (1989).

[4] D.W. Schaefer, MRS Bulletin 13(2), 22 (1988).

[5] C.J. Brinker and G.W. Scherer, J. Non-Cryst. Solids 70, 301 (1985).

[6] T.M. Tillotson, L.W. Hrubesh, and I.M. Thomas, in Better Ceramics Through Chemistry III, ed. by C.J. Brinker, D.E. Clark, and D.R. Ulrich (MRS, Pittsburgh, 1988) p. 685.

[7] T.M. Tillotson and L.W. Hrubesh, in Better Ceramics Through Chemistry IV, ed. by C.J. Brinker, D.E. Clark, D.R. Ulrich, and B.J. Zelinski (MRS, Pittsburgh, 1990) in press.

[8] L.W. Hrubesh, T.M. Tillotson, and J.F. Poco, ibid., in press.

[9] R.W. Pekala and F.M. Kong, J. de Physique Coll. Suppl. 50(4), C4-33 (1989).

[10] R.W. Pekala, J. Mat. Sci. 24, 3221 (1989).

[11] R.W. Pekala and F.M. Kong, Polym. Prpts. 30(1), 221 (1989).

[12] R.W. Pekala and C.T. Alviso, in Better Ceramics Through Chemistry IV, ed. by C.J. Brinker, D.E. Clark, D.R. Ulrich, and B.J. Zelinski (MRS, Pittsburgh, 1990) in press.

[13] L.J. Gibson and M.R. Ashby, Proc. Royal Soc. Lond. $382($ A), 43 (1982). 
[14] T. Woignier, J. Phalippou, and R. Vacher, J. Mat. Res., 4(3), 688 (1989).

[15] T. Woignier, J. Phalippou, R. Sempere, and J. Pelous, J. Phys. Fr. 49. 289 (1988).

[16] R.W. Pekala, C.T. Alviso, and J.D. LeMay, J. Non-Cryst. Solids, accepted.

[17] J.D. LeMay, R.W. Pekala, and L.W. Hrubesh, Pacific Polym. Prpts. 1, 295 (1989). 


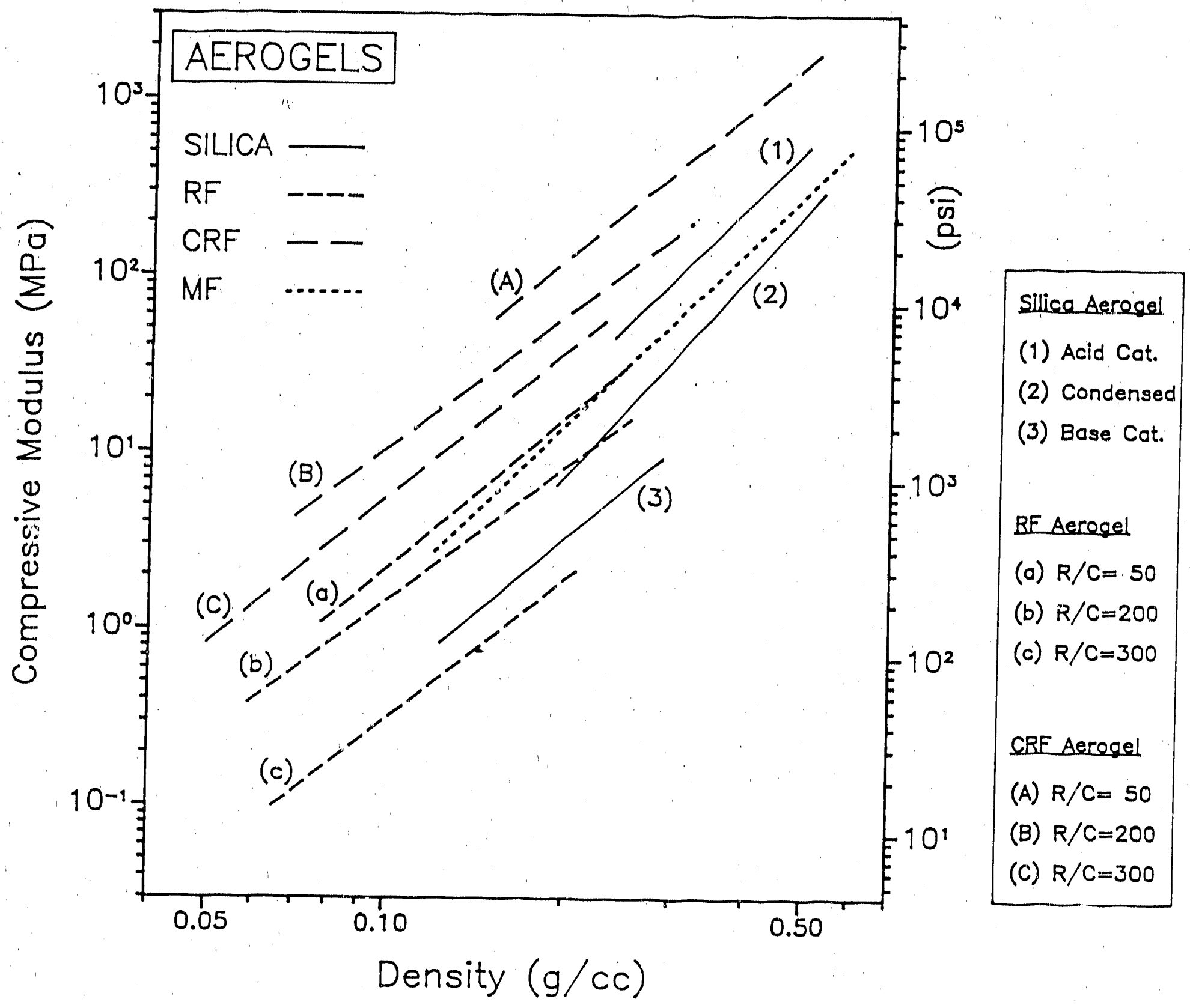

Figure 1. A log-log plot of compressive modulus vs. density for various inorganic and organic aerogels. 

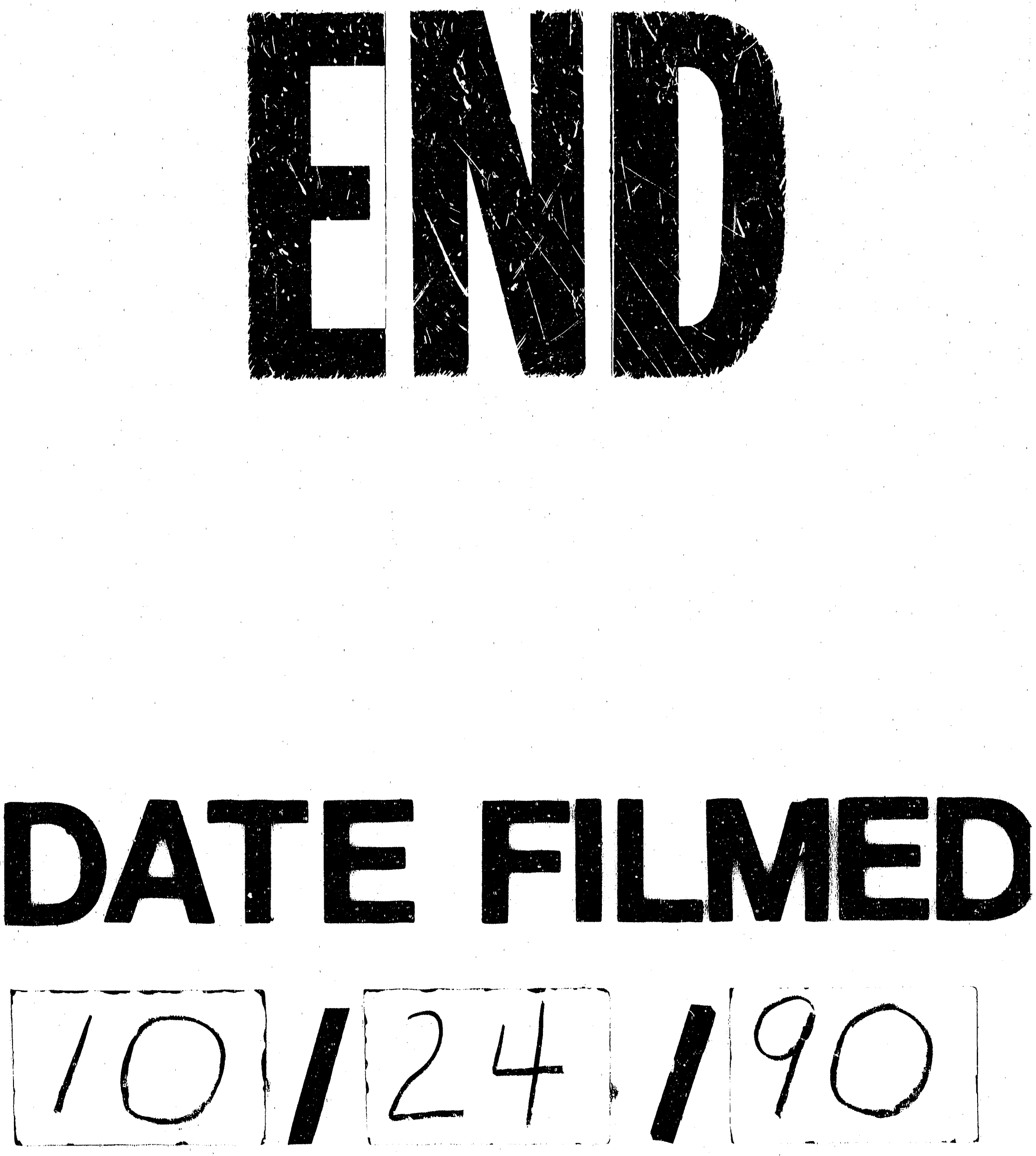
